\title{
On the Critical Thinking of the Undergraduates and the Cultivating Paths of the Universities in China
}

\author{
Wenbin $\operatorname{Sun}^{1, *}$, Huasheng $\operatorname{Sun}^{2}$, Wenhu $\mathrm{Gu}^{2}$ \\ ${ }^{1}$ Department of Teaching Quality Control and Evaluation, Huaiyin Institute of Technology, Huai'an Jiangsu 223003, \\ China \\ ${ }^{2}$ Faculty of Architecture and Civil Engineering, Huaiyin Institute of Technology, Huai'an Jiangsu 223001, China \\ *Corresponding author
}

\begin{abstract}
Critical thinking is the fountain of innovation. No criticism, no innovation. It is of great significance to attach importance to the undergraduates' critical thinking in order to enhance their comprehensive quality, innovative ability and learning skills. In this paper, the structural components and developed characteristics of the critical and reflective thinking were analyzed and summarized, the theoretical and practical significance of the critical and reflective thinking and the innovative ability training in the universities of China were discussed and researched. Some countermeasures and advises to the critical thinking and innovative ability training of undergraduates were suggested. An explicit paths and methods of the undergraduates' critical thinking cultivation have been integrated into the curriculum in Huaiyin Institute of Technology (HYIT), China. The cultivation of critical thinking was combined with learning skills and innovative ability in this way.
\end{abstract}

Keywords: Critical thinking, Comprehensive quality, Innovation ability, Learning ability

\section{INTRODUCTION}

In New Era, cultivating more innovative talents is the primary task of China's higher education. It has become the basic strategy of the Party and government to build a new richer and stronger China to cope with the challenges brought by economic globalization. With the high-speed improvement of economy, technology, science and society, the social improvement relying on natural resources and labor force has been gradually decline, and high-quality innovative talents will become the key to the success of social competition. Innovative thinking is a necessary ability for innovative talents, is the highest form of human thinking. It emphasizes the multiple perspectives, such as full range of thinking, reasoning and judgment, and these skills, it is the key to reflective and critical thinking. Therefore, it has an important meaning of innovative talents, when subject to criticism as a starting point, innovation will be much plumper and stronger. To build a moderately prosperous society in China and come true the China Dream and the Chinese National Rejuvenation, it is essential to train more and more innovative talents with critical thinking. Under the background of revolution for the China mode in higher education, it can be particularly important to develop and strengthen students' critical thinking to improve their innovative ability ${ }^{[1]}$.

\section{THE GOAL OF HIGHER EDUCATION AND THE CRITICAL THINKING}

\footnotetext{
Damon ${ }^{[2]}$ deemed that the primary aim of higher education institutes is to develop the students' growth in intelligence. Kronholm ${ }^{[3]}$ gave a more concrete definition of intellectual growth which improved the undergraduates' capacity in the form of critical thinking as a reflective thinker who is capable of critical judgment should be a vital target of higher education. Haworth and Conrad ${ }^{[4]}$ considered that a program contains critical dialog between the undergraduates and university, students can own much richer studying experience that dramatically strengthened their development and growth. A great many researchers emphasize the cultivation and training of the ability of students in thinking instead of the ability of students in absorbing objective facts. So, it is crucial to educate some types of intellectual growth, learning ability, and critical thinking.

Critical thinking supposes to assent the rigorous principles and codes of excellent commands which maybe directed, disciplined, monitored, and corrective by itself. It .It needs a high-efficient ability in problem-solving and communication as well as a strict duty to conquer inherent egoism. It is the process of analyzing, evaluating, reasoning and judging to the essence, value, truth, and accuracy by learning knowledge and making comprehensive determination. Some the earliest ideas and thoughts about critical or reflective thinking are ascribed to Dewey ${ }^{[5]}$. His assumption was that reflective thinking contains bringing a
} 
kind of closure with problematic or uncertain conditions where none way can be applied to give a correct solution and no way can be used to prove a definiteness that a suggested solution maybe necessarily correct.

\section{PROBLEMS IN CRITICAL THINKING OF UNDERGRADUATES}

To the engineering education in universities, it is very important to the uncertainty and none of a unique and correct solution in practice. For example, a design scheme in engineering project, it is typical that no one solution is absolute correct to each problem; instead of a much well answer should be chosen among many possible solutions. A common aim of faculty is to cast about for some paths to encourage undergraduates to reflect on their course materials by critical thinking. Skills of critical thinking maybe necessary for each student both during his/her time in university and his/her careers after graduation. The undergraduates of civil engineering are no exception. Unfortunately, undergraduates do not always gain these skills of critical/reflective thinking by their own, but require developing, training and encouraging [6].

Different people in different periods correspond to different stages of thinking; only unceasing thinking and continuous developing can form skilled critical thinking. In China, the understanding and research of critical thinking started relatively late. So far, many colleges and universities are still in the initial period to develop and educate the critical thinking, which is a process of continuous advancement in higher education of China.

Through a survey on critical thinking of college students, the results show that college students have the following main problems: students' tendency to training of critical thinking is generally weak; the tendency of critical thinking in male and female students has their own characteristics [7]. The dimensions of critical thinking are not balanced; different majors have different critical thinking tendencies. At the same time, students generally report that they do not fully feel the critical atmosphere in campus and classroom, which reflected the shirt of education on critical thinking for undergraduates in colleges and universities.

Lack of dynamic investigation on the raining of critical thinking $t$ in universities. Critical thinking is a part of personal character, whether one's inherent habit of thinking can change significantly in a short time or not, different people change at different paces. For the research and training of critical thinking, teachers should conduct dynamic research on the developing of students' critical thinking.

Ignore the construction of classroom culture with critical thinking. Classroom is the main physical spaces of teaching activities. Classroom culture with critical/reflective thinking is essential nutrient for the development of critical thinking. A classroom culture with critical thinking can make students and teachers realize the collision of thinking and wisdom, and realize mutual promotion and common growing of students and teachers.

In critical thinking training, teachers ought to instruct students to comprehend the concept, focus on the depth of problems, and emphasize communication and cooperation. Teaching materials should come from life. Teaching tasks should have a clear purpose. Teaching process should be lively and interesting. Teaching activities should be communicated equally.

\section{IMPORTANCE OF CULTIVATING CRITICAL THINKING}

Cultivating critical thinking is a crucial factor for undergraduates to develop their learning skills and innovative ability, and to improve their psychological and personality growth and comprehensive quality ${ }^{[8]}$.

\subsection{Be Benefit to Cultivate Innovative Talents}

Cultivating innovative talents is the core of China nation strategy. The more innovative a country is, the stronger its economy, education, and military might be. While training of critical thinking is the primary condition of cultivating and educating innovative thinking and innovative talents, it may be unrealistic and untested to discuss innovation without critical thinking. Now, we should continually study the experience and knowledge from predecessors, be good at discovering the defects and mistakes, and dare to overturn them. At the same time, we should continually improve the innovation ability, break through the egocentric and thinking out of the key area of self-delusion, and admit our mistakes. Only in the developing process of critical thinking, undergraduates can learn to judge based on existing principles, dare to use their imagination and be good at thinking.

\subsection{Be Benefit to Adapt to Information-based Society}

With the high-speed development of IT, people should face rapid changes in IT every day. The internet continuously penetrates every aspect of our work, study and life, and even affects living habits, thinking methods, and value orientation of everyone. So, critical thinking is particularly important to the higher education, it can effectively obtain valuable information and improve the ability to identify information. It can help students learn and improve information retrieval ability in the information age, enhance their competitiveness, and adapt to the information-based society.

\subsection{Be Beneficial to the Undergraduates' Mental Health and Personal Growth}


Because of the rapidly changing in society, contemporary undergraduates maybe more likely to emerge psychological problems. Many researchers conducted a large amount of studies on undergraduates' mental health, and they consider that college students ought to go through three stages of separation, transition and integration to truly adapt to college life. Critical thinking can help them critically comprehend and absorb the information which is exposed to in the process of acquiring knowledge, is conducive to their y psychological health and personal growth.

\subsection{Be Conducive for Graduates to Adapt to the Unknown Society}

Many cases showed that the existing educational mode in many educational institutions has seriously diverged from the demands of students' growth and society development, resulting in some undergraduates being very bewildering when entering the society and very difficult to quickly adapt to the society. If a college graduate lacks critical thinking, he or she may be overwhelmed by a sea of knowledge, and thus unable to make accurate and effective choices. Therefore, cultivating and strengthening critical thinking not only influence the future and destiny of graduates, but also be harmful to the development and improvement of society and country.

\section{CULTIVATE CRITICAL THINKING OF UNDERGRADUATES}

Training the critical thinking of undergraduates is a long-term process. Authors consider that the higher education of China must carry out the cultivation of critical thinking, colleges and universities should change the educational ideas, promote the critical thinking from the following aspects.

The reasonable training plan and curriculum are helpful to foster the critical thinking in college and university students. The training of critical thinking should be included in the curriculum and faculty; relevant training programs can help students to understand critical thinking from perceptual to rational. Colleges and universities should set up flexible and changeable curriculum system according to their own conditions, adjust the proportion of elective courses, increase the number of elective courses, and give students more rights to make their own choices. Many practical courses of critical thinking that are closely related to students' study and life should be created. Students can integrate critical thinking into the whole study, finally systematically and autonomously learn the general principles of critical thinking.

To use critical thinking to link subject content with practical activities. A mode of thinking can only pass on theoretical knowledge to college students and make them lack of the practice of social life. Therefore, undergraduates should be encouraged to train and apply critical/reflective thinking to study, understand and confirm the right and error of subconscious critical thinking by their learning, life and practice. Such activities in studying, life and practice not only closely combine between critical thinking cultivating and practice activities, but also enhance undergraduates' capability of cognizance to the natural world, thus improving the creative ability. Thinking originates from life. In social practice, students can establish the logical relationship between textbook theory, thinking method and life, and understand the significance of critical thinking to their growth and future.

To transform assessment methods of students' critical thinking. In the before, universities and colleges widely used test scores to evaluate students' mastery of theoretical knowledge, the tests use a standardized answer to question, this approach directly restricts the training and growing of students' critical/reflective thinking. The way of increasing process of examination to foster critical thinking of undergraduates, such as some appropriate links to join the teaching, practice, internship and innovative plan, and adjust the proportion of the study evaluation results are encouraged to use a new thinking mode with reflection, criticism and innovation to think and solve problems and questions, find new ideas and new methods to work out problem, it aroused students in virtually subconscious way of thinking, which helps students understand the critical thinking to the charm of your growth.

To improve undergraduates' ability of cognizance by critical/reflective thinking training. The mode of reflective, critical and creative thinking is an important manifestation of the comprehensive capability of first-class talents. As the main part of creative practice, undergraduates must actively gain knowledge by reflective and critical thinking through different approaches. As education and teaching institutions, colleges and universities should regularly invite some specialists and scholars to give reports and lectures on creative activities and critical thinking, actively set many kinds of club activities with the theme of critical thinking, organize undergraduates to attend critical innovation practices, motive undergraduates' independent ability in studying, thinking and innovation.

\section{ACKNOWLEDGEMENT}

This work is part of the Higher Education Research Project of HYIT under 2018XGJ16, part of the Higher Education Research \&Teaching Reform Project of EDJS under 2019JSJG307, and also part of the Philosophy \& Social Science Research Project of EDJF under 2019SJA1662.

\section{REFERENCES}

[1] S.G Luo. The urgency and approach of critical 
thinking training for college students, J. Guangxi Uni. (Phi. \& Soc. Sci.). 29 (2007) 134-138. (In Chinese)

[2] W. Damon. Colleges must help foster a spirit of inquiry in the nation's school, Chronicles of Higher Edu. 36 (1990) A-48.

[3] M.M. Kronholm. The impact of developmental instruction on reflective judgement, Rev. Higher Edu. 19 (1996) 199-225.

[4] J.G. Haworth and C.F. Conrad. Emblems of Quality in Higher Education: Development and Sustaining High-quality Programs, Allyn and Bacon, Boston, 1997.

[5] J. Dewey. How We Think, Dover Publications, Lexington, 1933.

[6] J.S. Thomas. Sustainability and critical thinking in civil engineering curriculum, J. Professional Issue in Eng. Edu. \& Practice, 127 (2001) 104-108.

[7] M. Zhang, J.F Ru and Y. Yin. Study on university students' critical thinking disposition and its causes, J. Chongqing Uni. (Soc. Sci. Ed.). 22 (2016) 202-207. (In Chinese)

[8] X.C. Zhu. Importance and strategies: on cultivating college students' critical thinking, J. South China Normal Uni. (Soc. Sci. Ed.)., 51 (2006): 123-126. (In Chinese) 